\title{
Aspects of Using Tool Axis Inclination Angle
}

\author{
Marek Sadílek ${ }^{1, *}$ - Robert Čep ${ }^{1-}$ Igor Budak $^{2}-$ Mirko Soković $^{3}$ \\ ${ }^{1}$ Faculty of Mechanical Engineering, VŠB-Technical University of Ostrava, Czech Republic \\ ${ }^{2}$ Faculty of Technical Science, Novi Sad, Serbia \\ ${ }^{3}$ Faculty of Mechanical Engineering, Ljubljana, Slovenija
}

This contribution deals with the research and proposal to change a position of tool axis against milled surface during multi-axial milling. Our target is achieving an increase in milling efficiency (improvement of functional surface properties, increase in milling accuracy, increase in tool durability, decrease in energy load on a machine, and shortening of milling time). This research attempts to make production of shape planes more efficient. This concerns production of molds, impression dies, and other complicated parts in various engineering industries, primarily automotive and aircraft ones.

(C)2011 Journal of Mechanical Engineering. All rights reserved.

Keywords: tool axis inclination angle, ball-end milling, surface roughness, cutting forces

\section{INTRODUCTION}

Pre-defined milling cycle possibilities are used during programming of multi-axial milling centers in the CAM systems [1]. However, are programmers able to utilize all available setting options perfectly? Do they put in all important information necessary for effective milling? Do these programmers know what values are the most effective?

These questions for programmers lead to an underestimated and neglected option to change tool axis position against the normal of milled surface. This work, among other things, tries to find an answer to this question and confirm it scientifically. The result then should be determination of an effective angle or rather effective range of settings of the spatial angle of the tool axis position in relation to a milled surface.

All milling parameter settings have to lead to increased milling efficiency, i.e., to increase in accuracy, improvement of functional properties of milled surface (roughness, waviness, residual stress, micro-hardness, etc.), decreasing of milling time, shortening of machine energy load, economical and ecological aspects, etc. [2,11].

Surface roughness and residual stress affect functional surfaces, durability and dependability of parts, their noisiness, break-in period, friction losses, electrical resistance, heat transfer, fatigue strength, wear and corrosion resistance, etc. [1, 12].

\section{MILLING BY INCLINED TOOL}

During standard milling with ball end milling cutters, when material and the tool are in right angles, a spherical cutting edge has zero cutting speed at the tool axis. The tool merely pushes in the milled material at this place. Due to this, undesirable effects such as: chip contraction, increase of cutting temperature, increase in vibrations, and increased creation of a build-up edge, can appear $[3,7,8]$. These phenomena result in worsened quality of milled surface and decreased tool durability. The Fig. 1 shows possibilities of tool inclination toward the surface normal.

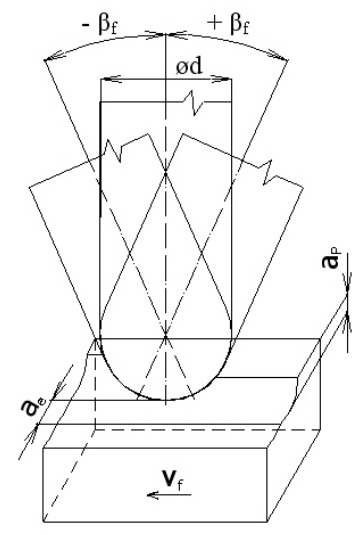

(a) Tilt in feed direction

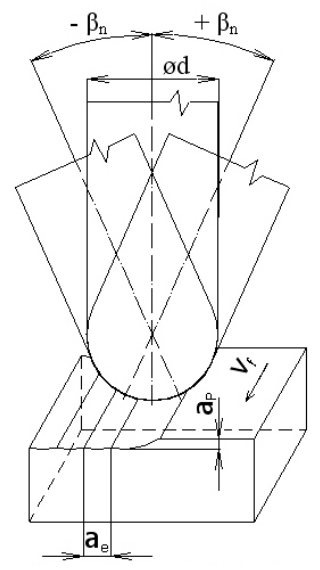

b) Tilt in pick feed direction
Fig. 1 Milling strategy with tool axis inclination angle

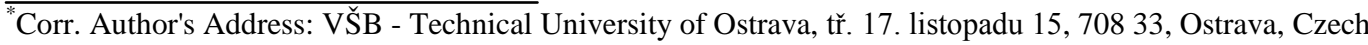
Republic, marek.sadilek@vsb.cz
} 
The mentioned phenomena can be eliminated by change of the tool axis position in relation to the milled piece, i.e., by inclination of the tool or the piece.

The effective diameter of the cutting tool during milling without tool inclination is calculated according to the following relationship [9]:

$$
d_{\text {eff }}=2 \cdot \sqrt{a_{p}\left(\mathrm{~d}-\mathrm{a}_{\mathrm{p}}\right)}
$$

Where: $d_{\text {eff }}$ - effective tool diameter [mm],

$a_{p}$ - axial depth of cut [mm],

$d$ - tool diameter [mm].

A feed direction is very important. If the feed direction is (so called) pulled one (Fig. 2a), the tool action is more silent and the surface of milled material is better, as opposed to (so called) pushed feed direction (Fig. 2b). These two ways can be used for inclination in the feed direction and also for inclination that is perpendicular to the feed direction.

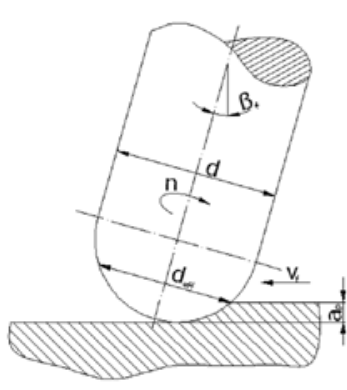

a ) Pulled tool

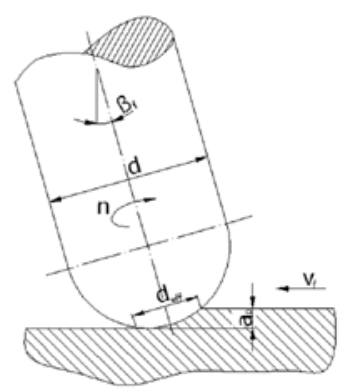

b) Pushed tool
Fig. 2 Feed direction

Thanks to change in position the effective tool diameter changes and so does the resulting (actual) effective cutting speed (Fig. 3).

The effective diameter of the cutting tool during milling with pulled tool is calculated according to the following relationship [9]:

$$
d_{\text {eff }}=d \cdot \sin \left[\arccos \left(\frac{d-2 a_{p}}{d}\right)+\beta_{f}\right]
$$

Where: $d_{\text {eff }}$ - effective tool diameter [mm],

$a_{p}$ - depth of cut [mm],

$\beta_{f}$-inclination angle in feed direction $\left[^{\circ}\right]$, $d$ - tool diameter [mm].

Milling with pushed tool corresponds with negative values of $\beta_{f}$ in the relationship (2). This signifies that, according to the mathematical expression, using of pushed tool is disadvantageous.

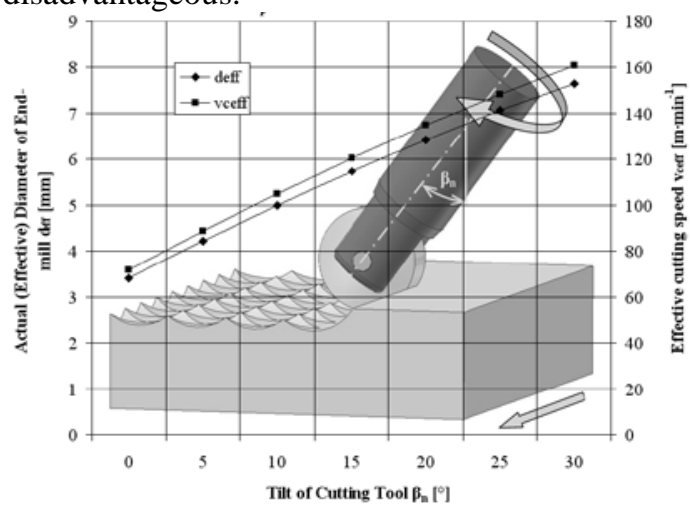

Fig. 3 Relationship of the effective tool diameter $d_{\text {eff }}$ and the effective cutting speed $v_{\text {ceff }}$ on the angle of tool inclination $\beta n,\left(d=10 \mathrm{~mm}, a_{p}=0.3\right.$ $\left.\mathrm{mm}, v_{c}=210 \mathrm{~m} \cdot \mathrm{min}^{-1}\right)$

Problematic of the scallop generation mechanism is quite complicated and falls into the field of applied mathematics. Many foreign publications describe this mechanism. These publications only describe the situation that the tool and workpiece are in a relative translation motion only (no rotation of ball-nosed cutter). The generating mechanism of the rotation ballnosed end milling, however, is much comlicated because the orientation of the cutting edge is dynamically and periodically changed during the spindle rotation [13].

Literature [14] presents a new geometrical model for the surface scallop estimation that considered the dynamic cutting edge rotation effect in the ball-nose end milling process. Literature [15] presented the model to include the effect of the tool axis inclination.

One of many published approaches used to determine theoretical surface roughness is described in [9].

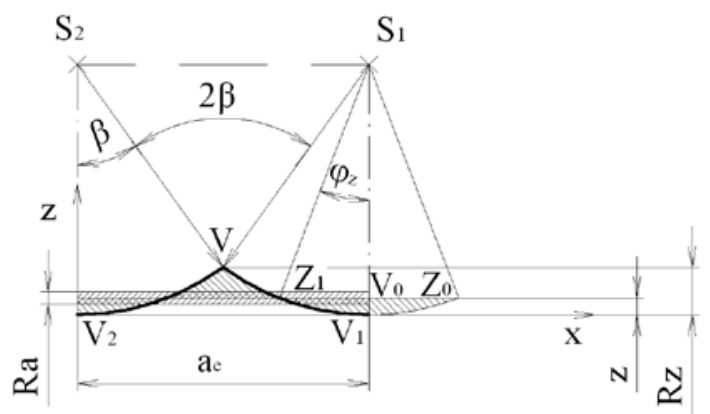


Fig. 4 Occurrence of theoretical surface roughness in pick feed direction on the plane [9]

According to this approach the resulting relationship for calculation of the average arithmetic deviation of surface roughness for milling with ball end milling cutter (Fig. 4) is [9]:

$$
\begin{aligned}
& R a=\frac{R^{2}}{a_{e}}\left\{\operatorname{arc} 2\left[\arccos \left(\frac{1}{2} \cos \arcsin \frac{a_{e}}{2 \cdot R}+\frac{R}{a_{e}} \arcsin \arcsin \frac{a_{e}}{2 \cdot R}\right)\right]-\right. \\
& \left.-\sin 2\left[\arccos \left(\frac{1}{2} \cos \arcsin \frac{a_{e}}{2 \cdot R}+\frac{R}{a_{e}} \operatorname{arc\operatorname {arcsin}} \frac{a_{e}}{2 \cdot R}\right)\right]\right\} \cdot 1000
\end{aligned}
$$

Where: $R a$ - arithmetical mean deviation of the profile $[\mu \mathrm{m}]$,

$R$ - cutter radius [mm],

$a_{e}$ - depth of cut [mm],

In the case of milling on inclined plane, $a_{e}$ is substituted with $a_{e}^{\prime}$ modified by the angle of the inclined plane $\alpha$ [9]:

$$
a_{e}^{\prime}=\frac{a_{e}}{\cos \alpha}
$$

Where: $\alpha$ - angle of the milled surface $\left[{ }^{\circ}\right]$, $a_{e}^{\prime}$ - angle of the inclined plane $\left[^{\circ}\right]$, $a_{e}$-depth of cut [mm].

For practical application the calculation for the maximum height of the profile $\mathrm{Rz}$, that can be found in the CSN EN ISO 4287 and CSN EN ISO 4288 standards, is sufficient:

$$
R z=R \cdot\left(1-\sqrt{1-\frac{a_{e}}{4 \cdot R^{2}}}\right)
$$

Where: $R z$ maximum height of the profile $[\mathrm{mm}]$, $R$ cutter radius [mm], $a_{e}$ depth of cut [mm].

\section{EXPERIMENTAL WORK}

Experiment characterization:

- tool axis angle in pick feed direction,

- conventional milling and climb milling combination,

- strategy of feed designated as pulled tool,

- using cutting fluid,

- workpiece 1.7131,

- ball end milling cutter (cutting inserts, 2 flutes, coating 8040),

- cutting geometry of exchangeable cutting edge: $\gamma_{p}=0^{\circ}$ a $\gamma_{\mathrm{f}}=-7^{\circ} \div 14^{\circ}$,

- cantilever length $\ln =110 \mathrm{~mm}$.

Representative examples of the surface roughness parameter Rz dependency on the angle of tool inclination $\left(\beta_{n}\right)$ have been selected from many performed experiments (Fig. 5 and Fig. 6).

The biggest maximum height of the profile $\mathrm{Rz}$ was measured in the feed direction and in the direction perpendicular to it. The lines are shown with the expanded combined uncertainty $U c$.

\begin{tabular}{|c|c|c|c|c|c|c|c|c|c|c|}
\hline \multicolumn{11}{|c|}{ Cutting Conditions } \\
\hline \multirow{2}{*}{$\begin{array}{l}\text { collection of } \\
\text { surfaces }\end{array}$} & \multirow{2}{*}{$\begin{array}{l}\text { depth } \\
\text { of cut }\end{array}$} & \multirow{2}{*}{$\begin{array}{l}\text { diameter of } \\
\text { endmill }\end{array}$} & \multirow{2}{*}{$\begin{array}{l}\text { spindle } \\
\text { rev. }\end{array}$} & \multirow{2}{*}{$\begin{array}{l}\text { cutting } \\
\text { speed }\end{array}$} & \multicolumn{4}{|c|}{$\begin{array}{l}\text { theoretic surface } \\
\text { roughness }\end{array}$} & \multirow{2}{*}{$\begin{array}{l}\text { width of } \\
\text { cut }\end{array}$} & \multirow{2}{*}{$\begin{array}{l}\text { feed per } \\
\text { tooth }\end{array}$} \\
\hline & & & & & \multicolumn{2}{|c|}{$\begin{array}{l}\text { pick feed } \\
\text { direction }\end{array}$} & \multicolumn{2}{|c|}{$\begin{array}{c}\text { feed } \\
\text { direction }\end{array}$} & & \\
\hline AMF & $a_{p}$ & $\mathrm{~d}$ & $\mathrm{n}$ & $\overline{V_{c}}$ & $\mathrm{Rz}$ & $\mathrm{Ra}$ & $\mathrm{Rz}$ & $\mathrm{Ra}$ & $\mathrm{a}_{\mathrm{e}}$ & $\overline{f_{z}}$ \\
\hline- & {$[\mathrm{mm}]$} & {$[\mathrm{mm}]$} & {$\left[\mathrm{min}^{-1}\right]$} & {$\left[\mathrm{m} \cdot \mathrm{min}^{-1}\right]$} & \multicolumn{2}{|c|}{$[\mu \mathrm{m}]$} & \multicolumn{2}{|c|}{$[\mu \mathrm{m}]$} & [mm] & {$[\mathrm{mm}]$} \\
\hline $\mathrm{a}$ & \multirow{2}{*}{0,3} & \multirow{2}{*}{10} & \multirow{2}{*}{6685} & \multirow{2}{*}{210} & 0,78 & 0,2 & 0,78 & 0,2 & 0,1765 & 0,1765 \\
\hline b & & & & & 1,56 & 0,4 & 1,56 & 0,4 & 0,2497 & 0,2497 \\
\hline
\end{tabular}
Measuring of the surface roughness parameters was performed on Hommel - Tester T2000.

Table 1. Cutting conditions 

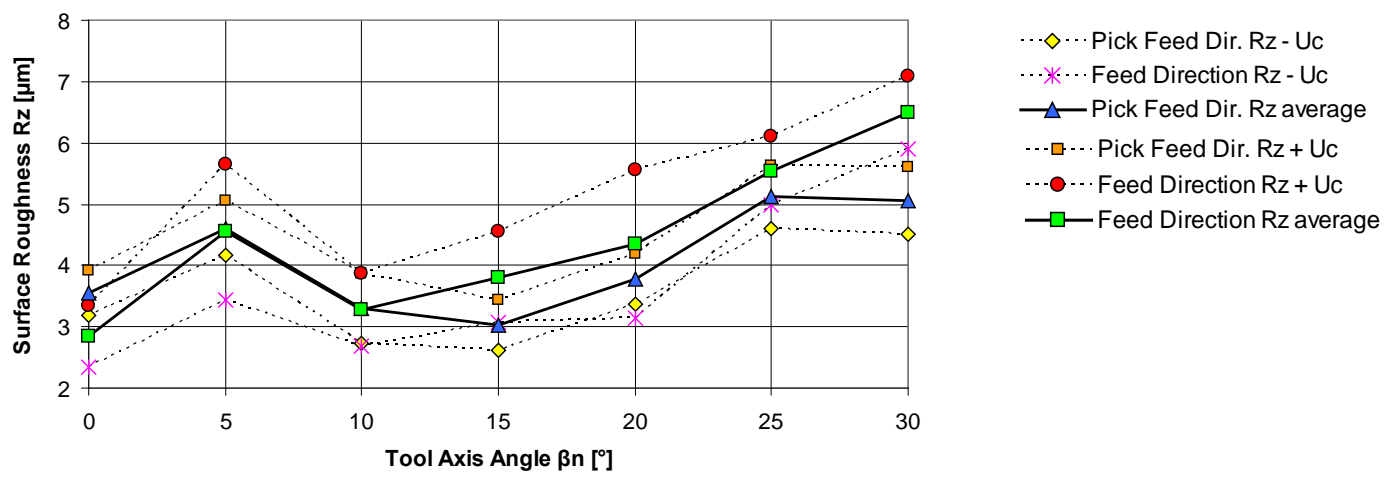

Fig. 5 Surface roughness (Rz) dependence on tool axis inclination angle, collection of surfaces " $a$ "

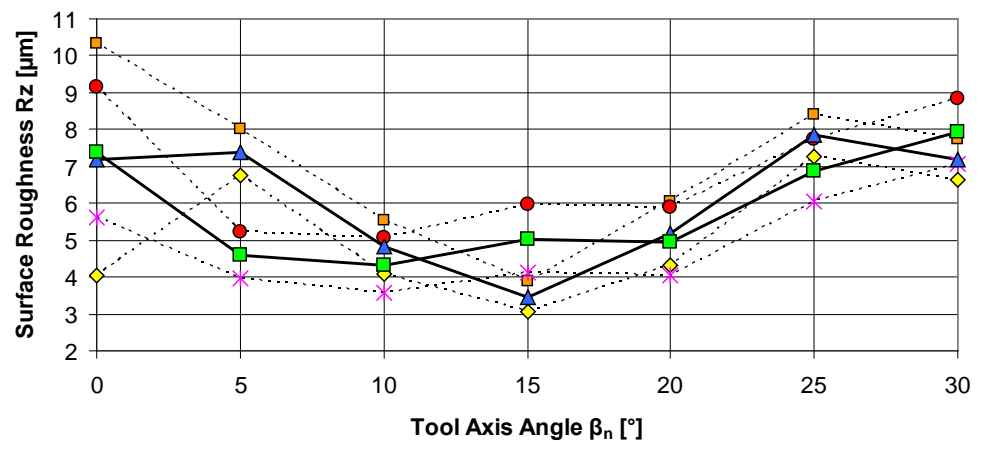

$\cdots \diamond \cdots$ Pick Feed Dir. Rz - Uc

…… Feed Direction Rz - Uc

$\rightarrow-$ Pick Feed Dir. Rz average

-....... Pick Feed Dir. Rz + Uc

- - . Feed Direction Rz + Uc

$\neg \square-F e e d$ Direction Rz average

Fig. 6 Surface roughness $(\mathrm{Rz})$ dependence on tool axis inclination angle, collection of surfaces " $b$ "

The graphs on Fig. 5 and Fig. 6 show that the most suitable cutter inclination is $\beta_{\mathrm{n}}$ around $15^{\circ}$. When the inclination is larger increased surface roughness, especially due to the change of inserts geometry, where there is cutting outside of so called transitional edge. The best longitudinal (feed direction) roughness was achieved with the inclination $\beta_{\mathrm{n}}=10^{\circ}$.

Deviations of theoretically calculated roughness from the actually measured value are presented on Fig. 7. The graph shows smaller measured roughness as opposed to the theoretical one for larger cut widths and feed per tooth. This result is related to the problematic of the minimum chip thickness. For double cut widths and feed per tooth $\left(a_{e}\right.$ and $\left.f_{z}\right)$ relatively equal surface roughness can be achieved.

Bearing length ratio changes more in longitudinal direction then in transversal one (Fig. 8). The most advantageous values of bearing length ratio appear in the longitudinal direction with the tool inclinations of $5^{\circ}$ and $15^{\circ}$. Here the bearing length ratio are largest. These results indicate beneficial impact of the tool inclination on functional aspects of milled surfaces. 


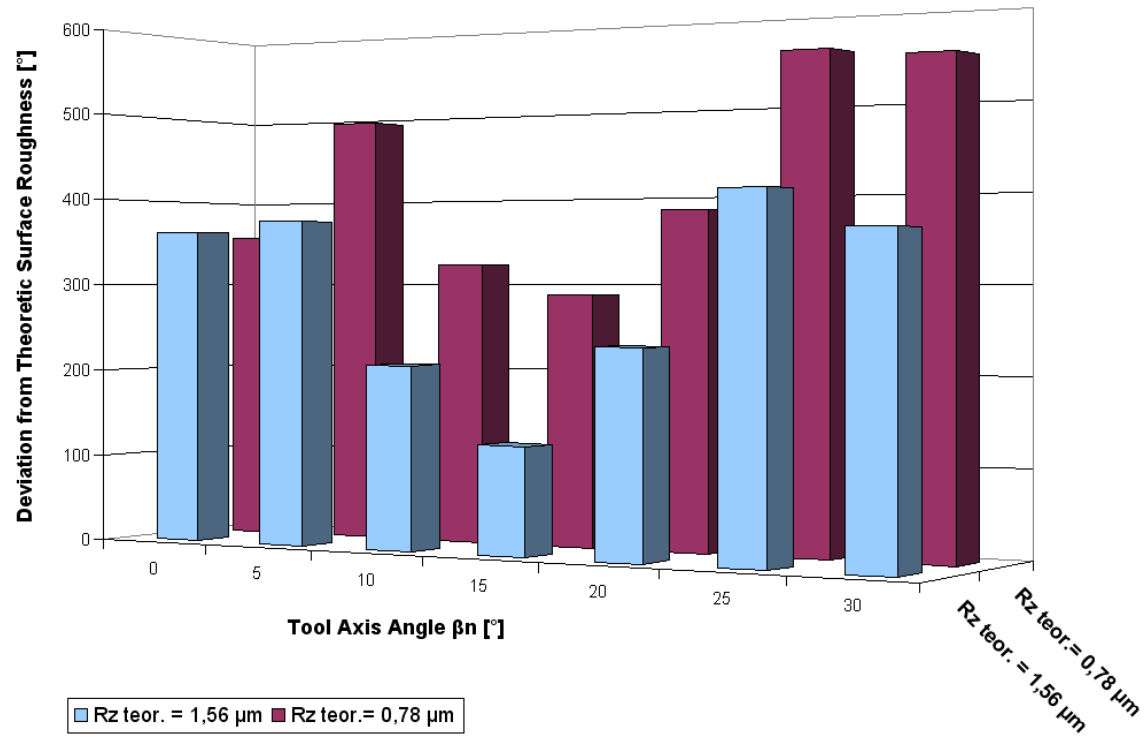

Fig. 7 Deviations of theoretical surface roughness (Rz) at different tool axis angles, pick feed direction (d $=10 \mathrm{~mm}, a_{e}, f_{z}=0.18 \mathrm{~mm}$ and $a_{e}, f_{z}=0.25 \mathrm{~mm}$, collection of surfaces , $a$ and $b$ “)

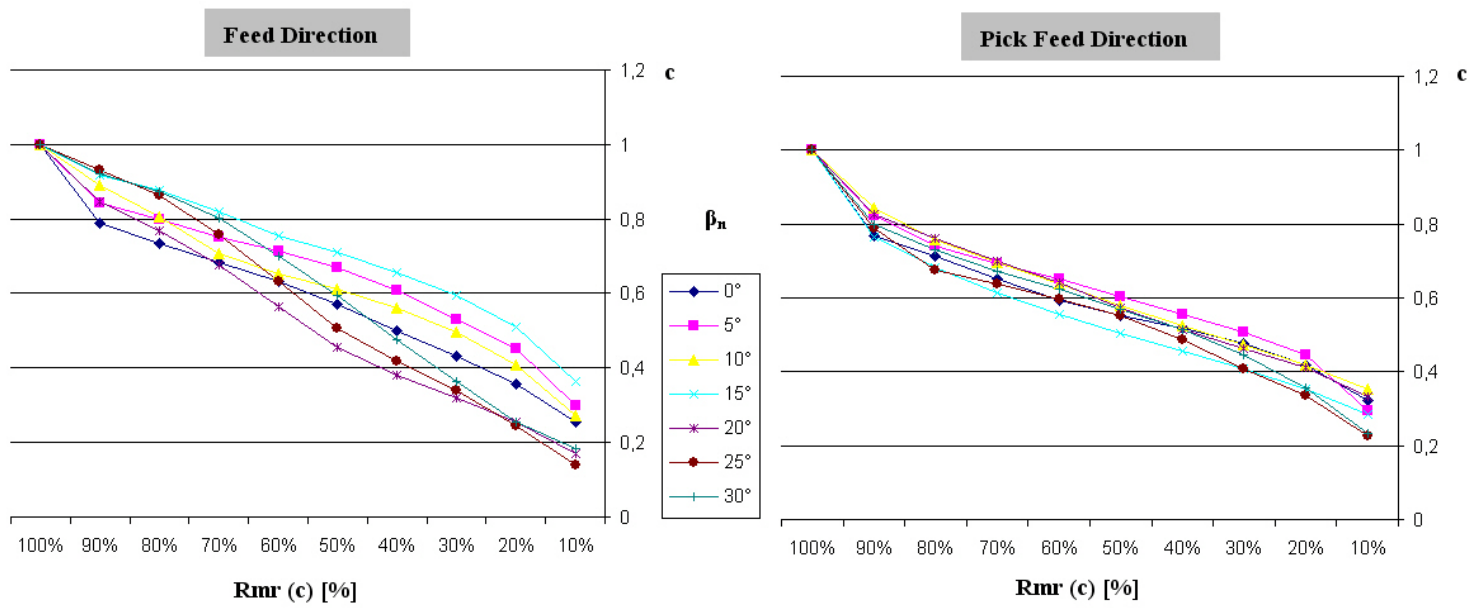

Fig. 8 Curves of the profile bearing length ratio (level 30\%) at different tool axis angles 


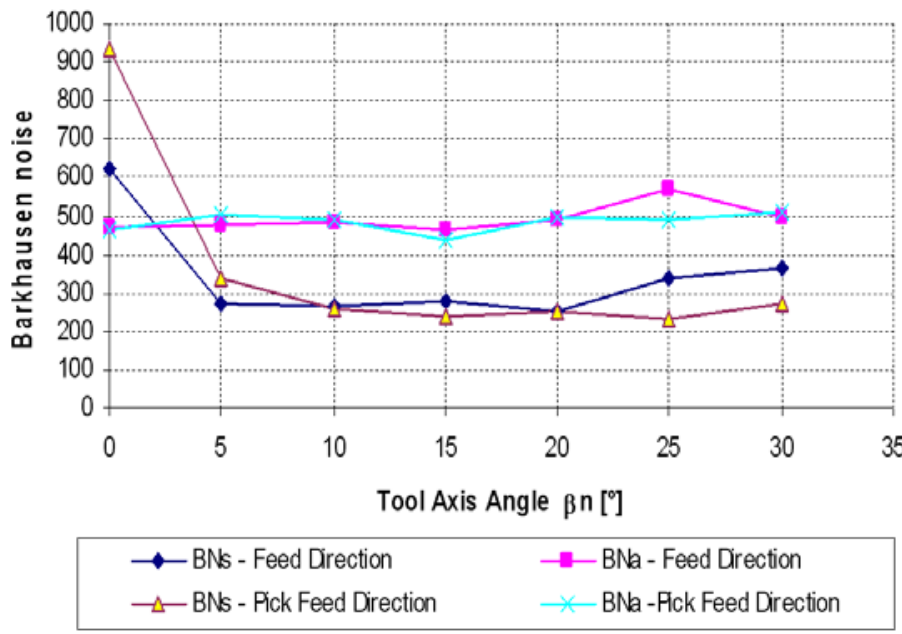

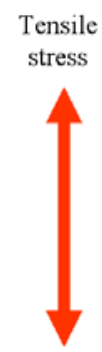

Pressure stress

Fig. 9 Barkhausen noise relation to tool axis angle - feed direction and pick feed direction (material X3CrNiMo13-4, $d=25 \mathrm{~mm}, v_{c}=153 \mathrm{~mm}, a_{p}=0.3 \mathrm{~mm}, a_{e}=0.6 \mathrm{~mm}, f_{z}=0.6 \mathrm{~mm}$ )

The question is to what extent the variable tool inclination influences the change in surface properties. Shape and curvature of tool edge have the biggest influence on surface integrity. Out of cutting parameters the fundamental influence is shown primarily by the cutting speed [2],[11],[10].

Residual stress shows at the workpiece surface layer areas as manifestation of used cutting technology. One of the possibilities how to indicate structural and tension states of ferromagnetic materials in the surface layer is using the magnetoelastic method.

It follows from the experiments that the cutter inclination results in decrease in the residual stress, see Fig. 9. During perpendicular position of the ball end milling cutter (inclination $=0^{\circ}$ ) in relation to a milled surface there is relatively high value of Barkhausen noise (i.e., undesirable tensile stress that needs to be eliminated) due to pushing-in at the tool axis with zero cutting speed.

Already tool inclination of five degrees results in significant decrease of the residual stress influence on surface (milled) layer. The Barkhausen noise values do not change with further change of the tool position significantly. Curves of the values measured in feed and pick feed directions are similar.
Residual stress was measured in $(0,01 \div 0,04) \mathrm{mm}$ depth.

In order to obtain stress values in $[\mathrm{N}]$ we need to perform calibration and recalculate the BS values using the calibration curves. This calibration, however, is economically and time demanding, therefore it is not absolutely necessary for confirmation of influence of inclination on residual stress. Dynamometer Kistler 9255B and DASYLab, Excel, and Matlab programs were used for measuring of cutting forces (Fig. 10).

As an example out of many measurements the curves of resultant forces during climb milling are shown on Fig. 11. Lower ranges of individual cutting force components were achieved by the cutting tool inclination angle changes. This leads to cutting process stability. For conventional milling several fold decrease of value range can be shown.

Course of the values component Fy (feed direction) decreases with tool inclination and then grows. Such a course (similar bathtub curve) is also noted for the results of measurements of roughness parameters, depending on the tool axis inclination angle. This confirms the fact that the decline in component Fy causes the improvement of surface roughness. 

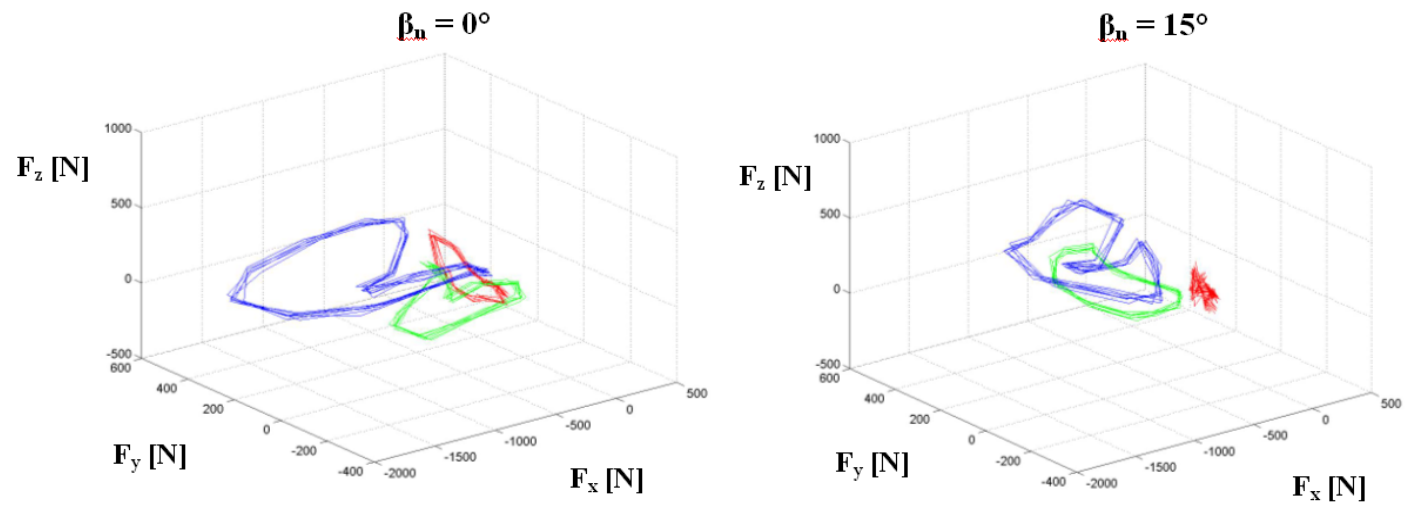

Combination of conventional and climb milling

- Conventional milling

Climb milling

Fig. 10 Direction and size of cutting forces result (Fv) dependence on cutting time (toll axis angle $\beta_{n}=0^{\circ}$ and $\left.15^{\circ}, d=10 \mathrm{~mm}, a_{p}=0.3 \mathrm{~mm}, f_{z}=0.2 \mathrm{~mm}, v_{c}=250 \mathrm{~m} \cdot \mathrm{min}^{-1}\right)$

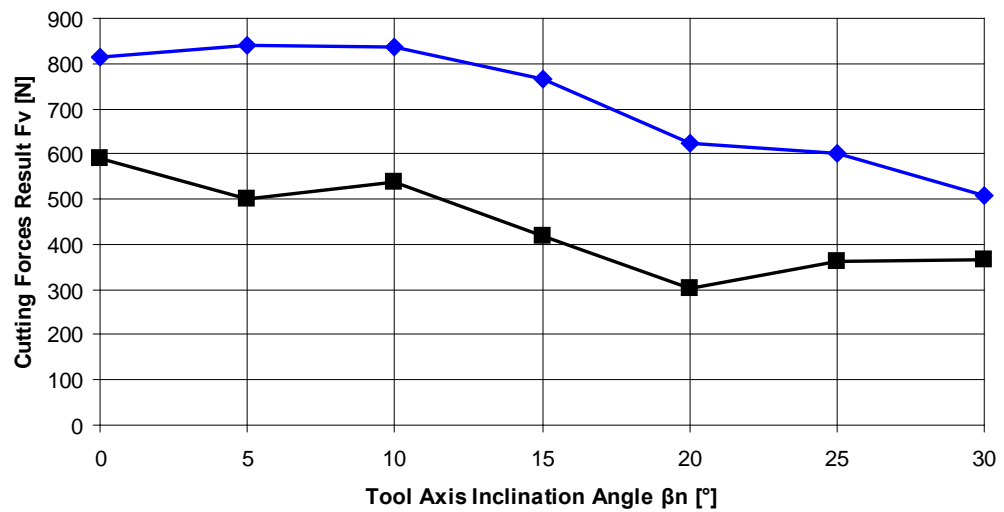

$\neg$ Diameter of Endmill $10 \mathrm{~mm} \rightarrow$-Diameter of Endmill $20 \mathrm{~mm}$

Fig. 11 Resulting cutting force depending on tool axis inclination angle during climb milling (workpiece 1.2343, $47-51 \mathrm{HRC}, d=10$ and $20 \mathrm{~mm}, a_{p}=0.3 \mathrm{~mm}, f_{z}=0.2 \mathrm{~mm}, v_{c}=250 \mathrm{~m} \cdot \mathrm{min}^{-1}$ )

\section{DISSCUSION AND CONCLUSIONS}

After final experiment evaluation one can conclude that the tool inclination has a significant influence on the longitudinal and transversal surface roughness. With increasing cutter diameter smaller inclination can be selected.

Benefits of using tool axis inclination angle include:

- increasing cutting speed,

- decreasing of surface roughness in both directions (pick feed direction and feed direction),
- decreasing cutting time (using bigger $a_{e}, f_{z}$ by the same surface roughness),

- increasing durability of cutting tool,

- increasing accuracy of cutting,

- constant cross sectional area of chip,

- constant cutting conditions,

- decreasing size of cutting forces components,

- favorable orientation of cutting forces direction,

- increasing functional surface properties of machined surface,

- inhibition of self-excited oscillations, and

- decreasing of cutting temperature. 
During milling it is necessary not to exceed the maximum tool inclination in relation to a workpiece; the inserts geometry needs to be maintained. When this inclination is exceeded increased surface roughness results. This eventuality can occur while milling steeper surfaces. With used inserts there was cutting outside so called transition edge during higher inclinations (e.g., for $\mathrm{d}=10 \mathrm{~mm}$ the critical $\beta_{n}=17^{\circ}$ ).

For most surface groups there was also considerable dependency of the tool inclination on residual stress.

The tool inclination against a workpiece has significant influence on size and direction of individual cutting force components. This can be used for optimization of tool inclination spatial angle in order to achieve better quality of milled surface, increase of tool durability, and lower energy demands during milling. Based on measured cutting forces the tool inclination spatial angle can be optimized online, which leads to adaptive optimization $[1,10]$.

The application research area is milling of shape surfaces with suppression of grinding operation. The integrity of ground surface is often unsatisfactory, for example from the point of view of heat and tension (residual stress) influence on surface layers [8]. Therefore research of the proposed technology contributes to the effort to eliminate grinding (i.e., final operation of manual finishing of shape surfaces), or to minimize it.

\section{REFERENCES}

[1] Kopač, J., Kržič, P. (2008) CAM Algorithm as Important Element by Achieving of Good Machined Surface Quality, Journal of Mechanical Engineering, ISSN 0039-2480, vol.54, no.4, Ljubljana Slovenia, pp. 280287.

[2] Župerl, U., Čuš, F, Reibenschuh, M. (2011). Neural control strategy of constant cutting force system in end milling, Robotics and Computer-Integrated Manufacturing, ISSN 0736-5845, vol. 27, no. 3, pp. 485-493.

[3] Tadić, B., Vukelić, D., Hodolič, J., Mitrović, S., Erić, M. (2011). ConservativeForce-Controlled Feed Drive System for Down Milling, Journal of Mechanical
Engineering, ISSN 0039-2480, vol. 57, no. 5, pp. 425-439.

[4] Čuš, F., Župerl, U. (2011) Real-Time Cutting Tool Condition Monitoring in Milling, Journal of Mechanical Engineering, ISSN 0039-2480, vol.57, no.2, Ljubljana Slovenia, pp. 142-150.

[5] Svalina, I., Sabo, K., Šimunović G. (2011) Machined surface quality prediction models based on moving least squares and moving least absolute deviations methods, The International Journal of Advanced Manufacturing Technology, ISSN 14333015, DOI 10.1007/s00170-011-3353-z.

[6] Šimunović, G., Šarić, T, Lujić, R. (2009). Surface quality prediction by artificialneural-networks, Technical Gazette, ISSN 1330-3651 vol. 16, no. 2, p. 43-47.

[7] Wei, Z. C., Wang, M. J., Zhu, J. N., Gu, L. Y. (2011) Cutting force prediction in ball end milling of sculptured surface with Zlevel contouring tool path, International Journal of Machine Tools \& Manufacture, ISSN 0890-6955, Vol. 51, Issue 5, pp. 428432.

[8] Čep, R., Neslušan, M., Barišić, B. (2008) Chip Formation Analysis During Hard Turning. Strojarstvo, vol. 50, no. 6, pp. 337 - 345. ISSN 0562 - 1887.

[9] Peterka, J. (2004) Nový př́stup výpočtu střední aritmetické odchylky drsnosti obrobeného povrchu při kopírovacím frézováním: Strojírenská technologie, roč. IX, č.2, s. 28-32.

[10] Antić, A., Hodolič, J., Soković, M. (2006) Development of a neural-networks toolwear monitoring system for a turning process, Journal of Mechanical Engineering, ISSN 0039-2480, vol. 52, no.11, Ljubljana Slovenia, pp. 763-776.

[11] Zetek, M., Řehoř, J., Strnad, T. (2006) Increasing cutting tool efficiency. In $\mathrm{PhD}$ 2006. Plzeň : University of West Bohemia, pp. 1-9, ISBN 80-7043-486-4.

[12] Dobránky, J., Hatala, M. (2007) Influence of selected technological parameter to quality parameters by injection moulding. In: Annals of DAAAM for 2007 \& proceedings of the 18th International DAAAM Symposium: Intelligent Manufacturing \& Automation: Focus on Creativity, Responsibility, and Ethics of 
Engineers: Zadar, Croatia. 2007. 2 p. ISBN 3-901509-58-5.

[13] CHEN, J.S.; HUANG, Y.K.; CHEN, M.S. A study of the surface scallop generating mechanism in the ball-end milling process, International Journal of Machine Tools \& Manufacture, 45 (2005) p. 1077-1084, 2005.

[14] MIZUGAKI, Y.; HAO, M.; KIKKAWA, K. Geometric generating mechanism of machined surface by ball-nosed end milling, Annals of the CIRP 50 (1), 2001.

[15] MIZUGAKI, Y.; KIKKAWA, K. TERAL, H.; HAO, M. Theoretical estimation of machined surface profile based on cutting edge movement and tool orientation in ballnosed end milling, Annals of the CIRP 52 (1), 2003. 